\title{
Lidil
}

Revue de linguistique et de didactique des langues

\section{Philippe Blanchet, Discriminations : combattre la} glottophobie

Éd. Textuel, 2016, 191 p.

Marielle Rispail

\section{(2) OpenEdition}

\section{Journals}

Édition électronique

URL : http://journals.openedition.org/lidil/4015

DOI : 10.4000/lidil.4015

ISSN : $1960-6052$

\section{Éditeur}

UGA Éditions/Université Grenoble Alpes

Édition imprimée

Date de publication : 30 mai 2016

Pagination : 209-210

ISBN : 978-2-84310-326-1

ISSN : $1146-6480$

\section{Référence électronique}

Marielle Rispail, « Philippe Blanchet, Discriminations : combattre la glottophobie », Lidil [En ligne], 53 |

2016, mis en ligne le 01 janvier 2017, consulté le 29 octobre 2020. URL : http://

journals.openedition.org/lidil/4015 ; DOI : https://doi.org/10.4000/lidil.4015 
pour captivante qu'elle soit, contribue à «repassionner» l'enseignement de la littérature puisque ce type d'approche vise pour l'essentiel à évaluer les effets physiologiques du geste lectoral de manière érudite et analytique, sans pour autant stimuler le plaisir de la lecture ou celui de l'enseignement des lettres.

Jean-François Vernay

Essayiste et chercheur en littérature

\section{Philippe Blanchet, Discriminations : combattre la glottophobie,} Éd. Textuel, 2016, 191 p.

L'ouvrage de Philippe Blanchet paru chez Textuel est fidèle à son titre qui combine une notion comprise de toutes et tous «discriminations» avec un néologisme qui intrigue «glottophobie». C'est quoi, cette bête? En fait, rien de plus clair : ce terme, clin d'œil sans doute à la «glottophagie» de Louis-Jean Calvet, dans le sous-titre de son célèbre Linguistique et colonialisme, désigne les exclusions ou discriminations linguistiques, autrement dit le processus qui consiste à exclure ou stigmatiser quelqu'un-e pour des raisons linguistiques. Celles-ci peuvent aussi bien être la pratique d'une langue peu valorisée (patois, dialecte, créole, etc.) que la pratique régionale ou marquée socialement d'une langue commune, par les phénomènes d'accent, de prononciation, de prosodie, etc.

L'auteur part en guerre contre ces rejets linguistiques, dont nous sommes souvent l'objet ou le sujet, ou les deux à la fois : il explique comment chacun-e de nous a une anecdote à ajouter à sa collecte, dès qu'on comprend qu'il s'agit de dire les fois où on a été mis à l'écart pour une raison de «parler». Outre les témoignages, il s'attache aussi à démonter le mécanisme politique qui a construit le mythe d'une langue une et unique, hors de laquelle tout usage serait déviant : «le but (était) de construire une variété standard la plus homogène possible» (p. 38). Et il montre surtout comment cette construction, image de la société dont elle émane et devenue prescriptive, a servi des enjeux de pouvoirs et de domination sociale. Car rejeter un usage linguistique revient à rejeter ses locuteurs : c'est ainsi que naissent les discriminations.

Éminemment pédagogique, porté par un humanisme revendiqué, cet ouvrage se veut à la fois érudit et abordable. Il s'inscrit dans le 
mouvement des derniers travaux de Blanchet, qui se réclament d'une sociolinguistique «d'intervention», non coupée de l'action sociale et de ses retombées. Il se présente en 5 parties dont les titres sont déjà en soi une démonstration : l'introduction est sous-titrée Les pratiques linguistiques, un domaine de discrimination largement ignoré, la partie II Voir les choses autrement..., la partie III Comment s'est déployée et se maintient la glottophobie?, la partie IV La glottophobie en pratique: étude d'exemples, la partie V Des pistes et des principes pour combattre la glottophobie. L'auteur y décortique les phénomènes de représentations, de manipulations, de domination et de complicité générale, dont se nourrissent les glottophobies, au profit de pouvoirs sociaux et politiques qui en tirent les ficelles. Nourris d'exemples et d'extraits de discours courants, les chapitres avancent vers des propositions à la fois collectives et individuelles pour penser et vivre une pluralité linguistique plus humaine, qui préfigurerait peut-être une société future plus humaine elle aussi. Car, écrit Blanchet, « un autre monde (linguistique) est possible», un monde où les langues, acceptées dans toute leur diversité, ne seraient plus prétexte à domination et sélection.

Rafraichissant en ces temps de poisseuse grisaille.

Marielle Rispail

CELEC, UJM Saint-Étienne

Louis-Jean Calvet, La Méditerranée : mer de nos langues, CNRS éditions, 2016, 328 p.

Louis-Jean Calvet a depuis des années entamé une recherche sur la circulation des langues dans le pourtour méditerranéen. Certain-e-s ont déjà pu profiter de quelques pépites de cette réflexion, lors de séminaires à l'université d'Aix-en-Provence ou lors de la conférence pour la remise de l'ouvrage qui lui a été dédié Pour la (socio) linguistique ${ }^{1}$, en 2010.

La voici à présent aboutie avec la sortie de son ouvrage La Méditerranée : mer de nos langues, somme de savoirs et mises en relation

1. M. Gasquet-Cyrus, A. Giacomi, Y. Touchard \& D. Véronique, Pour la (socio) linguistique (pour Louis-Jean Calvet), Paris, L'Harmattan, 2010, 328 p. 